(C) The Author(s), 2021. Published by Cambridge University Press on behalf of The Nutrition Society. This is an Open Access article, distributed under the terms of the Creative Commons Attribution licence (http://creativecommons.org/licenses/by/4.0/), which permits unrestricted re-use, distribution, and reproduction in any medium, provided the original work is properly cited.

\title{
Poor oral health and the association with diet quality and intake in older people in two studies in the UK and USA
}

\author{
Eftychia Kotronia $^{1 *}$, Heather Brown ${ }^{1}$, A. Olia Papacosta ${ }^{2}$, Lucy T. Lennon ${ }^{2}$, Robert J. Weyant ${ }^{3}$, \\ Peter H. Whincup ${ }^{4}$, S. Goya Wannamethee ${ }^{2}$ and Sheena E. Ramsay ${ }^{1}$ \\ ${ }^{1}$ Population Health Sciences Institute, Newcastle University, The Baddiley-Clark Building, Richardson Road, Newcastle Upon \\ Tyne NE2 4AX, UK \\ ${ }^{2}$ Department of Primary Care \& Population Health, Institute of Epidemiology and Health Care, University College London, \\ London, UK \\ ${ }^{3}$ Department of Dental Public Health, School of Dental Medicine, University of Pittsburgh, Pittsburgh, PA, USA \\ ${ }^{4}$ Population Health Research Institute, St George's University of London, London, UK
}

(Submitted 14 September 2020 - Final revision received 21 December 2020 - Accepted 6 January 2021 - First published online 20 January 2021)

\section{Abstract}

We aimed to investigate the associations of poor oral health cross-sectionally with diet quality and intake in older people. We also examined whether change in diet quality is associated with oral health problems. Data from the British Regional Heart Study (BRHS) comprising British males aged 71-92 years and the Health, Aging and Body Composition (HABC) Study comprising American males and females aged 71-80 years were used. Dental data included tooth loss, periodontal disease, dry mouth and self-rated oral health. Dietary data included diet quality (based on Elderly Dietary Index (BRHS) and Healthy Eating Score (HABC Study)) and several nutrients. In the BRHS, change in diet quality over 10 years (1998-2000 to 2010-2012) was also assessed. In the BRHS, tooth loss, fair/poor self-rated oral health and accumulation of oral health problems were associated with poor diet quality, after adjustment. Similar associations were reported for high intake of processed meat. Poor oral health was associated with the top quartile of percentage of energy content from saturated fat (self-rated oral health, OR 1.34, 95\% CI 1.02, 1.77). In the HABC Study, no significant associations were observed for diet quality after adjustment. Periodontal disease was associated with the top quartile of percentage of energy content from saturated fat (OR 1.48, $95 \%$ CI 1.09, 2.01). In the BRHS, persistent low diet quality was associated with higher risk of tooth loss and accumulation of oral health problems. Older individuals with oral health problems had poorer diets and consumed fewer nutrient-rich foods. Persistent poor diet quality was associated with oral health problems later in life.

Key words: Dental problems: Processed meat: Macronutrients: Micronutrients: Energy from fat: Change in diet quality: Protein intake: Vitamins

Oral health problems such as tooth loss, periodontal disease and dry mouth are very common conditions in older people ( $\geq 65$ years) and have significant impacts on health ${ }^{(1)}$. Poor oral health in older age has been associated with the development of chronic conditions, such as disability, CVD and increased risk of mortality ${ }^{(2-4)}$. Moreover, older people are at risk of following a poor diet, particularly avoidance of specific foods or frequent consumption of unhealthy food, which can adversely influence their nutritional intake, quality of life and general well-being ${ }^{(5)}$. Poor oral health can play an important part in changes in dietary habits and variety of food intake, but at the same time an unhealthy diet may also affect oral health ${ }^{(5)}$, suggesting a bidirectional relationship between poor oral health and diet in older people.
Tooth loss, in particular, has been found to be associated with low intakes of fruits and vegetables, vitamin C, vitamin E, as well as higher consumption of processed foods and fatty acids in adults ( $>18$ years $)^{(6-10)}$. It is possible that the association between oral health and fat intake may be due to higher consumption of processed meat which is a source of saturated fat which is easy to chew and requires little preparation ${ }^{(11-13)}$. Tooth loss was also associated with poor diet quality and low protein intake in older people ${ }^{(7,12,14,15)}$. However, these findings were not consistent in all studies ${ }^{(16,17)}$. Furthermore, having a good oral function (optimal number of teeth and ability to chew) was found to be associated with higher consumption of protein and vegetables and decreased consumption of energy content and fats in some studies ${ }^{(14,18,19)}$, but similar to tooth loss, results

Abbreviations: BRHS, British Regional Heart Study; EDI, Elderly Dietary Index; HABC, Health, Aging and Body Composition; HEI, Healthy Eating Index.

* Corresponding author: Eftychia Kotronia, email e.kotronia2@newcastle.ac.uk 
were not consistently reported by other studies ${ }^{(17,20)}$. Moreover, periodontal disease was associated with low intake of percentage of energy content from fat in adults ${ }^{(21)}$, whereas dry mouth, particularly hyposalivation, was associated with lower consumption of fruits and vegetables in older people ${ }^{(22)}$. Additionally, studies have found that poor diet quality and increased intake of saturated fat were associated with the progression of periodontal disease (chronic gum disease) and tooth loss in older adults ${ }^{(23,24)}$. Furthermore, diets rich in antioxidants and low in saturated fats led to an improvement in the severity of periodontal disease in adults ${ }^{(25)}$.

These studies support the presence of a bidirectional association of poor oral health with diet quality and intake. However, there is no consensus on the specific nutrients associated with poor oral health in older people. Furthermore, the majority of previous studies have focused on tooth loss and periodontal disease. There is lack of evidence on the associations of other markers of oral health such as dry mouth and self-rated oral health with dietary intake in older people. Hence, we aimed to examine the associations of objectively and subjectively assessed oral health markers with diet quality and dietary intake, as well as changes in diet quality over 10 years, and their associations with poor oral health in samples of community-dwelling older people in the UK and USA.

\section{Subjects and methods}

We used data from the British Regional Heart Study (BRHS) in the UK and the Health, Aging and Body Composition (HABC) Study in the USA. The study is reported according to the STROBE guidelines.

\section{The British Regional Heart Study}

This is an ongoing cohort study which at baseline comprised 7735 males aged 40-59 years. Individuals were recruited from twenty-four towns across the UK in 1978-80 and have been followed up since ${ }^{(26)}$. For the present study, data from the 20-year and 30-year follow-up were used. In 1998-2000, 4252 males (77\% response rate) aged 60-79 years participated in the 20 -year follow-up physical examination and completed postal questionnaires (see Fig. 1). A 30-year follow-up of the cohort was undertaken in 2010-2012 and was attended by 2147 surviving participants aged 71-92 years. Participants completed a postal questionnaire ( $68 \%$ response rate), participated in the physical and oral health examination ( $n$ 1722) $(55 \%$ response rate) and had blood samples taken ${ }^{(26)}$. Examinations were conducted by a trained research nurse and took place in each of the twenty-four towns of the study in community-based venues. Information on missing data and attrition is presented in online Supplementary Fig. S1. Ethical approval was provided by the National Research Ethics Service Committee, London. Written informed consent was obtained from individuals for their participation in the study, according to the Declaration of Helsinki ${ }^{(27)}$.

\section{The Health, Aging and Body Composition Study}

The HABC Study is a prospective population-based study investigating deterioration in physical function of older individuals and how changes in body composition influence health in older age. Baseline data collection took place in 1997-1998, where 3075 White and African American males and females aged 70-79 years were recruited (see Fig. 2). Random selection of White participants was performed through Medicare, whereas African American were selected through neighbourhoods with a ZIP code around Memphis and Pittsburgh ${ }^{(28)}$. At baseline, individuals who were not able to walk 0.25 miles or climb ten steps were excluded from the study. In year 2 (1998-1999), data from males and females aged 71-80years $(n$ 3075) were used. Measurements included an oral health $(n$ 1975) and physical assessment, collection of blood samples and completion of questionnaires. Oral examination was conducted at the research centre by a dental hygienist or a periodontist. Details on missing data and attrition are presented in online Supplementary Fig. S2. All participants provided written informed consent. Ethical approval was provided by University of Pittsburgh, University of Tennessee - Memphis, UCSF and $\mathrm{NIH}^{(28)}$.

\section{Oral health markers}

In both studies, oral health was assessed through an oral examination and completion of questionnaires and included objectively and subjectively assessed oral health markers. Objective markers (oral examination) included count of natural teeth and periodontal disease measures (loss of attachment and pocket depth $)^{(1,29)}$. Details of the examination of periodontal disease can be found elsewhere ${ }^{(1,29)}$. Subjective (self-rated) oral health markers (questionnaires) comprised self-rated oral health, dry mouth, difficulty eating due to mouth, teeth or dentures problems, sensitivity to hot/cold/sweets and limitation of food due to gum problems. In the HABC Study, one question was used to assess dry mouth (dry mouth when eating). In the BRHS, the Xerostomia Inventory Scale, which consists of eleven questions, was used to measure dry mouth and groups (number of symptoms) were created according to the responses $\operatorname{provided}^{(30)}$

\section{Dietary intake and diet quality}

In the BRHS, dietary intake was assessed at two time points at the 20-year (age 60-79years) and 30-year (aged 71-92 years) follow-up by a postal FFQ which was developed for use in the WHO's Monitoring Trends and Determinants in Cardiovascular Disease Survey, and has been validated in the British population $^{(31)}$. For the measurement of diet quality, the Elderly Dietary Index (EDI) was utilised, which is based on the US Modified MyPyramid for Older Adults and other recommendations for older people ${ }^{(32)}$. The EDI score comprises nine food components (meat, fish and seafood, legumes, fruit, vegetables, cereals, bread, olive oil and dairy $)^{(32,33)}$. Consumption of each food group was used to create the EDI score to indicate diet quality. Further details on the FFQ and EDI score can be found elsewhere ${ }^{(33)}$. Dietary intake included protein, carbohydrates, energy content from total and saturated fat, cholesterol, fruits and vegetables, sugar and a range of micronutrients (vitamins $\mathrm{C}$ and $\mathrm{E}, \mathrm{Fe}$, vitamin $\mathrm{A}, \beta$-carotene, vitamin $\mathrm{K}_{1}$ ). The total macronutrient and micronutrient intakes were calculated by a validated computer program which is based on UK food composition 


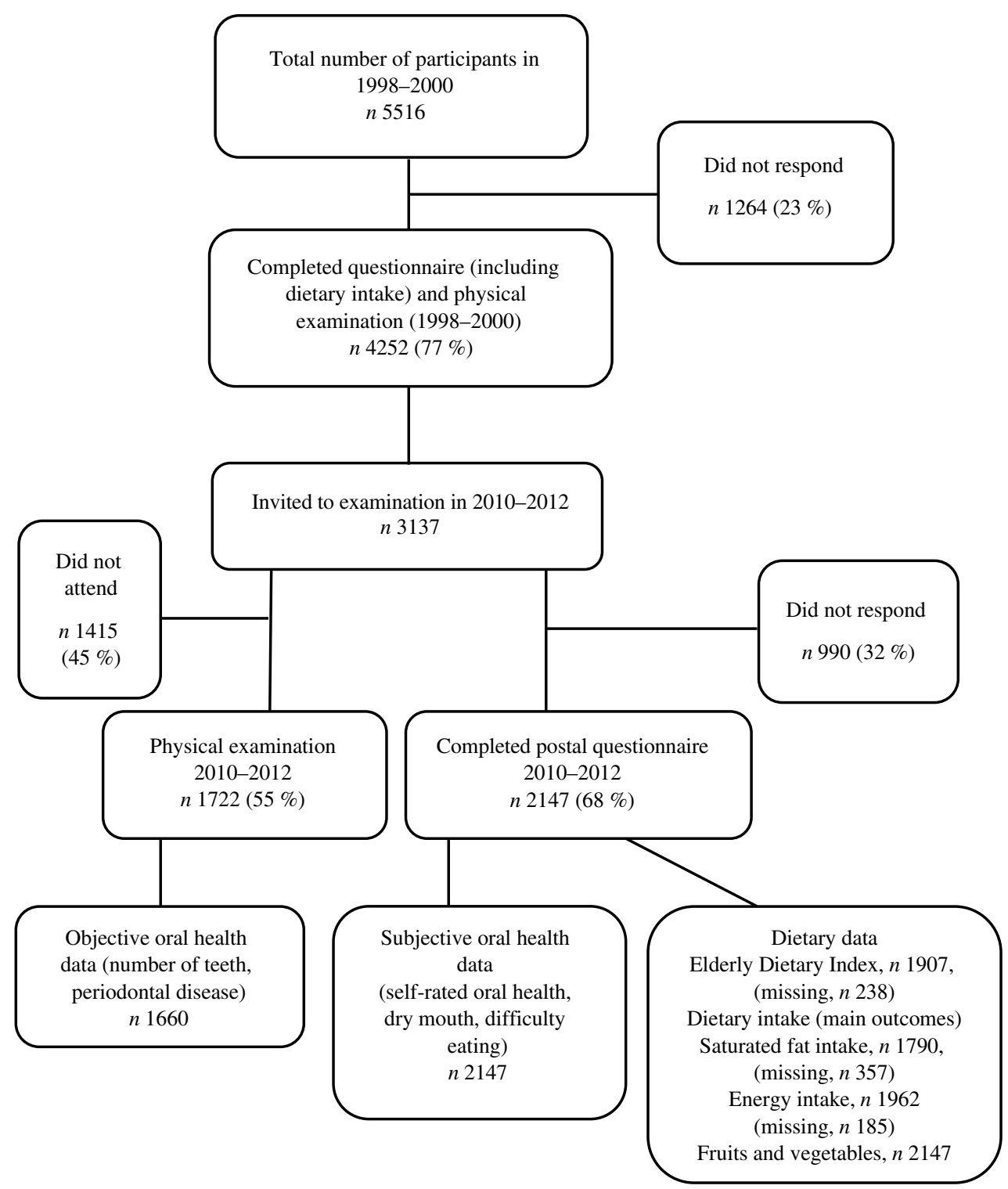

Fig. 1. Flow chart of British Regional Heart Study participants followed up from 1998-2000 until 2010-2012.

tables ${ }^{(33,34)}$. The frequency of foods consumed was multiplied by the standard portion sizes for each food and by the nutrient composition of the foods obtained from the UK food composition tables ${ }^{(32,34)}$. Then, according to these intakes, total energy intake was also calculated. Additionally, in order to examine whether potential associations between oral health and fat intake are a result of high consumption of processed meat, we created a variable about the intake of processed meat. In the BRHS, consumption of bacon, salami, tinned meat, corned beef, pork and beef sausages, meat pie and pasties was used to create this variable. In the HABC Study, processed meat consisted of ham, bacon, sausage, bologna and fried chicken. This variable was based on the number and frequency of processed meat consumed.

In the HABC Study, a 108-item, interviewer-administered modified version of the Block FFQ (Block Dietary Data Systems) was used for the assessment of dietary intake in year 2 (1998-1999) $^{(35,36)}$. More details on the FFQ can be found elsewhere ${ }^{(36)}$. The Healthy Eating Index (HEI) was used to assess diet quality and shows whether an individual adheres to the Dietary Guidelines for Americans of 1995 and the Food Pyramid of 1992 (36). HEI score is a validated tool for the assessment of diet quality for the US population and is defined according to different sex and age groups ${ }^{(36,37)}$. Therefore, it can be used to assess dietary intake of different age groups, including older people. HEI consists of ten components: nine food components (grains, vegetables, fruit, milk and meat, intakes of percentages of energy content from total and saturated fat, total cholesterol and total $\mathrm{Na}$ ) and one component which assesses diet variety. In the HABC Study, dietary intake also included trans-fat intake, percentage of energy from sweets and soda, and a number of micronutrients (vitamins $\mathrm{B}_{1}, \mathrm{~B}_{2}, \mathrm{~B}_{5}, \mathrm{~B}_{6}, \mathrm{C}$, $\mathrm{D}, \mathrm{E}, \mathrm{A}$ and $\mathrm{B}_{12}, \mathrm{Cu}, \mathrm{Mg}, \mathrm{Mn}, \mathrm{Fe}, \mathrm{Ca}, \mathrm{P}, \mathrm{K}, \mathrm{Zn}$, folic acid). Similar to the BRHS, we created a variable about the consumption of processed meat. In both studies, protein intake was measured as g/ kg body weight per $\mathrm{d}$. 
Fig. 2. Flow chart of the Health, Aging and Body Composition Study participants aged $71-80$ years at year 2. * Eligible for a periodontal disease assessment.

\section{Covariates}

In both studies, measures of socio-economic position, smoking, alcohol and history of doctor-diagnosed CVD and diabetes were self-reported through questionnaires ${ }^{(26,29)}$. In the BRHS, occupational social class was used to assess socio-economic position on the basis of longest-held occupation at baseline ${ }^{(38)}$. In the HABC Study, the highest level of education accomplished was the indicator of socio-economic position ${ }^{(29)}$. To create BMI, body weight and height assessed at physical examinations were utilised ${ }^{(39,40)}$. For both studies, total energy intake was derived from FFQ questionnaires, and regular use of prescribed medications causing dry mouth (xerostomia) was identified ${ }^{(41)}$.

\section{Statistical analysis}

Logistic and regression analyses were performed for the BRHS and HABC Study separately to assess the associations of oral health markers with diet quality and majority of nutrients. Ordinal regression was performed for the associations between (a) poor oral health and three categories of processed meat, and (b) change in EDI score over time and oral health problems (four categories) later in life. We observed no violations of the assumptions for logistic and ordinal regression analyses. Two variables for number of natural teeth were created: (a) 0, 1-7, 8-14, 15-20 and $\geq 21$ teeth; and (b) $<21$ teeth and $\geq 21$ teeth $^{(42)}$. Loss of attachment and pocket depth were markers of periodontal disease and the following categories were generated: in the BRHS pocket depth $>20 \%$ sites affected $>3.5 \mathrm{~mm}$ and loss of attachment $>20 \%$ sites affected $>5.5 \mathrm{~mm}$; in the HABC Study - both markers $>20 \%$ sites affected $\geq 3 \mathrm{~mm}^{(38,43)}$. Self-rated oral health was a binary variable grouped as excellent/good and fair/poor in both studies. In the BRHS, dry mouth was divided into $0,1-2$ or $\geq 3$ dry mouth symptoms. In the HABC Study, dry mouth was categorised as either having dry mouth when eating or not. Moreover, to examine the burden of poor oral health, we created a variable indicating an accumulation of oral problems - in the BRHS, four oral health problems were used: $<21$ natural teeth, $\geq 3$ dry mouth symptoms, any difficulty eating and sensitivity to hot/cold/ sweets ${ }^{(44)}$; in the HABC Study, the measure included: $<21$ natural teeth, dry mouth when eating, any difficulty eating and limitation of food due to gum problems. The variable was then categorised as $0,1,2$ and $\geq 3$ problems. In the BRHS, EDI scores were divided into quartiles, with the bottom quartile (worst diet quality) as the outcome variable in logistic regression models. In the HABC Study, HEI scores were categorised as good ( $>80$ ), needs improvement (51-80) and low $(<51)$ diet quality ${ }^{(37)}$; 'low HEI score' (poor diet quality) was the outcome whereas needs improvement and good HEI scores were grouped together (reference group) in logistic regression models. In both studies, macro- and micronutrients were divided into quartiles and either the bottom or top quartile were outcomes in logistic regression models in order to indicate worse dietary intake ${ }^{(45)}$. Consumption of processed meat was categorised as: $1=$ rarely/monthly (little intake), $2=1$ type of processed meat $\geq 2$ times per week (moderate intake), $3=\geq 2$ types of processed meat $\geq 2$ times per week; the third category ( $\geq 2$ types of processed meat $\geq 2$ times per week - indicating high intake) was the outcome in ordinal regression. Protein intake was a binary variable; in the BRHS low protein consumption was categorised as $<0.75 \mathrm{~g} / \mathrm{kg}$ per $\mathrm{d}$ and high as $\geq 0.75 \mathrm{~g} / \mathrm{kg}$ per $\mathrm{d}^{(46)}$, and in the HABC Study low as $<0.8 \mathrm{~g} / \mathrm{kg}$ per $\mathrm{d}$ and high as $\geq 0.80 \mathrm{~g} / \mathrm{kg}$ per $\mathrm{d}^{(47)}$. Recommended values of fruits and vegetables intake were used as cut-off values in logistic regression. In the BRHS, individuals with intake smaller than five portions/d and, in the HABC Study, participants with intake smaller than six portions/d were classified as having low intake of fruits and vegetables ${ }^{(48,49)}$. In the BRHS, regression models were adjusted for age, social class, smoking, alcohol, history of CVD and diabetes, BMI and energy intake. In the HABC Study, age, sex, race, education, smoking, alcohol, history of CVD and diabetes, BMI and energy intake were included as potential confounders in the models.

Additionally, in the BRHS, change in the EDI scores was examined over 10 years between age 60-79years and 
71-92 years. Change in EDI scores was calculated as a 4-level variable $(1=$ persistent poor EDI score, $2=$ decrease in score, $3=$ improvement, $4=$ persistent good score). Ordinal and logistic regression analyses were performed to test the association of change in EDI score with oral health markers at age 71-92 years. All analyses were performed using SAS, version 9.4 software (SAS Institute, Inc.).

In both studies, we compared the distribution of characteristics between those with and without missing data to examine potential differences between the two groups.

\section{Results}

Baseline characteristics and prevalence of oral health markers can be found in Table 1. The mean age of BRHS participants ( $n$ 2147) was 78.8 years, $52 \%$ were in non-manual social class, $20 \%$ had no remaining natural teeth and $35 \%$ reported fair/poor self-rated oral health. Moreover, $62 \%$ had at least one dry mouth symptom, whereas $36 \%$ reported at least two oral health problems. In the HABC Study ( $n$ 2998), mean age of study subjects was 74.7 years, $52 \%$ were female, $58 \%$ White and $42 \%$ reported post-secondary education. Also, $11 \%$ of the HABC Study sample had no remaining natural teeth, $31 \%$ fair/poor self-rated oral Composition (HABC) Study

(Mean values and standard deviations; numbers and percentages) health, $4 \%$ had dry mouth when eating and $22 \%$ at least two oral health problems.

\section{Oral health and diet quality}

OR and $95 \% \mathrm{CI}$ for the associations between oral health markers and diet quality in the BRHS and HABC Study are presented in Table 2 .

Objective oral health markers. In the BRHS, having 8-14 teeth was associated with the bottom quartile (poor diet quality) of EDI score (OR 1.57, $95 \%$ CI 1.05, 2.34), after adjusting for confounders. In the HABC Study, complete and partial tooth loss, and periodontal disease (loss of attachment) were associated with poor diet quality in the age-adjusted models $(0 v . \geq 21$ teeth, OR $1 \cdot 78,95 \%$ CI $1 \cdot 03,3 \cdot 08$; periodontal disease, OR $2 \cdot 21,95 \%$ CI $1 \cdot 33,3 \cdot 70)$. The associations for tooth loss were attenuated and did not remain after adjustment. For periodontal disease, the association was also attenuated after adjusting for confounders (OR $1 \cdot 69,95 \%$ CI $0 \cdot 98,2 \cdot 94)$.

Subjective oral health markers. In the BRHS, fair/poor selfrated oral health and at least three oral health problems were

Table 1. Population characteristics and prevalence of oral health problems in the British Regional Heart Study (BRHS) and the Health, Aging and Body

\begin{tabular}{|c|c|c|c|c|c|}
\hline \multicolumn{3}{|l|}{ BRHS ( $n$ 2147) } & \multicolumn{3}{|l|}{ HABC Study ( $n$ 2998) } \\
\hline & $n$ & $\%$ & & $n$ & $\%$ \\
\hline \multicolumn{3}{|l|}{ Age (years) } & \multicolumn{3}{|l|}{ Age (years) } \\
\hline Mean & \multicolumn{2}{|c|}{$78 \cdot 8$} & Mean & \multicolumn{2}{|c|}{74.7} \\
\hline SD & \multicolumn{2}{|c|}{4.8} & SD & \multicolumn{2}{|c|}{$2 \cdot 9$} \\
\hline Social class & & & Sex & & \\
\hline Non-manual & 1081 & 52 & Male & 1491 & 48 \\
\hline Manual & 1003 & 48 & Female & 1584 & 52 \\
\hline Smoking & & & Race & & \\
\hline Never & 768 & 36 & White & 1794 & 58 \\
\hline Long-term ex-smoker (gave up before 1983) & 1153 & 54 & African American & 1281 & 42 \\
\hline Recent ex-smoker & 122 & 6 & Education & & \\
\hline Current smoker & 91 & 4 & Less than high school & 775 & 26 \\
\hline Alcohol consumption & & & High school graduate & 1000 & 33 \\
\hline Daily/most days & 757 & 36 & Post-secondary & 1292 & 42 \\
\hline No consumption & 292 & 14 & Smoking* & & \\
\hline History of CVD & 500 & 24 & Never & 1348 & 44 \\
\hline History of diabetes & 321 & 16 & Current smoker & 318 & 10 \\
\hline $\mathrm{BMI}$ & & & Former & 1404 & 46 \\
\hline Normal & 486 & 29 & Alcohol consumption* & & \\
\hline Overweight & 875 & 51 & More than 1 per $d$ & 227 & 7 \\
\hline \multirow{7}{*}{ Obese } & 343 & 20 & No consumption in the past year & 1546 & 50 \\
\hline & & & History of CVD & 106 & 4 \\
\hline & & & History of diabetes & 142 & 5 \\
\hline & & & $\mathrm{BMI}$ & & \\
\hline & & & Normal & 963 & 34 \\
\hline & & & Overweight & 1192 & 42 \\
\hline & & & Obese & 673 & 24 \\
\hline Oral health measures & & & Oral health measures & & \\
\hline Edentulism (no natural teeth) & 338 & 20 & Edentulism (no natural teeth) & 207 & 11 \\
\hline$<21$ teeth & 1066 & 64 & $<21$ teeth & 1031 & 52 \\
\hline$>20 \%$ sites with loss of attachment $>3.5 \mathrm{~mm}$ & 303 & 24 & $>20 \%$ sites with loss of attachment $\geq 3 \mathrm{~mm}$ & 721 & 64 \\
\hline$>20 \%$ sites with pocket depth $>5.5 \mathrm{~mm}$ & 365 & 29 & $>20 \%$ sites with pocket depth $\geq 3 \mathrm{~mm}$ & 627 & 55 \\
\hline Fair/poor self-rated oral health & 719 & 35 & Poor self-rated oral health & 829 & 31 \\
\hline$\geq 1$ dry mouth symptoms & 1272 & 62 & Dry mouth when eating & 107 & 4 \\
\hline$\geq 2$ oral health problems & 766 & 36 & $\geq 2$ oral health problems & 617 & 22 \\
\hline
\end{tabular}

*Baseline data (year 1). 
Table 2. Association of oral health markers with Elderly Dietary Index (EDI) and Healthy Eating Index (HEI) scores in older British men aged 71-92 years in the British Regional Heart Study (BRHS) and older American men and women aged 71-80 years in the Health, Aging and Body Composition (HABC) Study

(Odds ratios and $95 \%$ confidence intervals)

\begin{tabular}{|c|c|c|c|c|c|c|c|c|c|}
\hline \multicolumn{5}{|c|}{ BRHS } & \multicolumn{5}{|c|}{ HABC Study } \\
\hline & \multicolumn{4}{|c|}{$\begin{array}{l}\text { Poor diet quality } \\
\text { (bottom quartile of EDI score) (11-22) } \\
(n 470 ; 25 \%)\end{array}$} & & \multicolumn{4}{|c|}{$\begin{array}{l}\text { Poor diet quality } \\
\text { (low HEI group) }(<51) \\
(n 216 ; 8 \%)\end{array}$} \\
\hline & $\begin{array}{l}\text { Age- } \\
\text { adjusted } \\
\text { OR }\end{array}$ & $95 \% \mathrm{Cl}$ & $\begin{array}{c}\text { Fully } \\
\text { adjusted OR }\end{array}$ & $95 \% \mathrm{Cl}$ & & $\begin{array}{l}\text { Age- } \\
\text { adjusted } \\
\text { OR }\end{array}$ & $95 \% \mathrm{Cl}$ & $\begin{array}{c}\text { Fully } \\
\text { adjusted OR* }\end{array}$ & $95 \% \mathrm{Cl}$ \\
\hline Tooth loss & & & & & Tooth loss & & & & \\
\hline$\geq 21$ teeth & 1.00 & & 1.00 & & $\geq 21$ teeth & 1.00 & & 1.00 & \\
\hline $15-20$ teeth & 1.47 & $1.03,2.08$ & 1.30 & $0.89,1.90$ & $15-20$ teeth & 1.74 & $1.11,2.74$ & $1 \cdot 18$ & $0.72,1.94$ \\
\hline $8-14$ teeth & 1.84 & $1.28,2.65$ & 1.57 & $1.05,2.34$ & $8-14$ teeth & 1.57 & $0.95,2.60$ & 0.99 & $0.57,1.73$ \\
\hline $1-7$ teeth & 1.74 & $1.07,2.85$ & 1.54 & $0.90,2.62$ & $1-7$ teeth & $2 \cdot 17$ & $1.27,3.70$ & 1.19 & $0.65,2.17$ \\
\hline 0 teeth & 1.76 & $1.24,2.49$ & 1.34 & $0.90,2.01$ & 0 teeth & 1.78 & $1.03,3.08$ & 0.87 & $0.46,1.64$ \\
\hline $\begin{array}{l}\text { Periodontal disease (\% of sites with loss of } \\
\text { attachment }>5.5 \mathrm{~mm} \text { ) }\end{array}$ & & & & & $\begin{array}{l}\text { Periodontal disease (\% of sites with loss of } \\
\text { attachment } \geq 3 \mathrm{~mm})\end{array}$ & & & & \\
\hline$\leq 20 \%$ & 1.00 & & 1.00 & & $\leq 20 \%$ & 1.00 & & 1.00 & \\
\hline$>20 \%$ & 1.33 & $0.96,1.84$ & 1.28 & $0.89,1.82$ & $>20 \%$ & $2 \cdot 21$ & $1.33,3.70$ & 1.69 & $0.98,2.94$ \\
\hline Self-rated oral health & & & & & Self-rated oral health & & & & \\
\hline Good/excellent & 1.00 & & 1.00 & & Good/excellent & 1.00 & & 1.00 & \\
\hline Fair/poor & 1.56 & $1.25,1.94$ & 1.51 & $1.14,1.99$ & Fair/poor & 1.68 & $1 \cdot 26,2 \cdot 24$ & 1.29 & $0.94,1.77$ \\
\hline Dry mouth symptoms & & & & & Dry mouth & & & & \\
\hline No dry mouth symptoms & 1.00 & & 1.00 & & No & 1.00 & & 1.00 & \\
\hline $1-2$ dry mouth symptom & 0.93 & $0.71,1.20$ & 0.85 & $0.61,1.17$ & Yes & 1.84 & $1.03,3.29$ & 1.63 & $0.86,3.10$ \\
\hline$\geq 3$ dry mouth symptoms & 1.02 & $0.79,1.33$ & 1.09 & $0.79,1.52$ & & & & & \\
\hline Cumulative oral health problems $\dagger$ & & & & & Cumulative oral health problems $\dagger$ & & & & \\
\hline 0 oral health problems & 1.00 & & 1.00 & & 0 oral health problems & 1.00 & & 1.00 & \\
\hline 1 oral health problem & 1.64 & $1.17,2 \cdot 28$ & 1.12 & $0.78,1.62$ & 1 oral health problem & 1.70 & $1.19,2.45$ & $1 \cdot 12$ & $0.75,1.67$ \\
\hline 2 oral health problems & 1.55 & $1.08,2.22$ & 0.97 & $0.64,1.48$ & 2 oral health problems & 1.64 & $1.03,2.63$ & 0.91 & $0.54,1.56$ \\
\hline$\geq 3$ oral health problems & 2.06 & $1.35,3.15$ & 1.83 & $1.11,3.01$ & $\geq 3$ oral health problems & 1.49 & $0.84,2.65$ & 0.73 & $0.38,1.38$ \\
\hline
\end{tabular}

† BRHS: Includes < 21 teeth, difficulty eating, symptoms of dry mouth and sensitivity to hot, cold or sweet; HABC Study: dry mouth when eating, $<21$ remaining teeth, any difficulty eating or chewing, limit of food due to gum problems. 
associated with the bottom quartile (poor diet quality) of EDI score (OR 1.51, $95 \%$ CI 1.14, 1.99; OR 1.83, $95 \%$ CI 1.11, 3.01, respectively), after full adjustment.

In the HABC Study, fair/poor self-rated oral health, dry mouth and accumulation of oral health problems were associated with low HEI score (poor diet quality) in age-adjusted models (OR $1 \cdot 68,95 \%$ CI $1.26,2.24$ for self-rated oral health, OR 1.84 , $95 \%$ CI $1.03,3.29$ for dry mouth), but these associations did not remain after adjusting for confounders.

\section{Oral health and dietary intake}

Table 3 presents the associations of poor oral health with energy intake, percentage of energy from saturated fat, and fruits and vegetables intakes in the BRHS. Associations between oral health problems and protein, vitamin C and $\alpha$-tocopherol intakes are presented in online Supplementary Appendix A, Fig. A1. Associations between oral health and processed meat are presented in online Supplementary Appendix B, Fig. B1.

Objective oral health markers. In the fully adjusted model, partial tooth loss (15-20 teeth $v$. $\geq 21$ ) was associated with the top quartile of energy intake (OR 1.54, $95 \%$ CI 1.11, 2.16). We did not observe any associations between markers of poor oral health and low protein intake. Complete and partial tooth loss were associated with increased consumption of processed meat and low fruits and vegetables intake (processed meat, OR 2.03, $95 \%$ CI 1·40, 2.95; OR 1·64, $95 \%$ CI 1·12, 2.38, respectively) after adjustment for confounders. The associations between oral health and processed meat did not remain after further adjustment for energy intake. A borderline association was observed for periodontal disease and low fruits and vegetables intake in the age-adjusted model (OR 1.52, $95 \%$ CI 1.00, 2.30). This association did not change significantly after full adjustment (OR 1.52, $95 \%$ CI 0.96, 2.40). Complete and partial tooth loss, and loss of attachment were associated with the bottom quartile of $\alpha$-tocopherol in the fully adjusted models (see online Supplementary Appendix A, Fig. A1). We did not observe any other associations between oral health markers and vitamins and minerals.

Subjective oral health problems. In the BRHS, $\geq 3$ dry mouth symptoms and $\geq 3$ oral health problems were associated with the top quartile of energy intake (OR 1.58, $95 \%$ CI 1·17, 2.13; OR $2 \cdot 32,95 \%$ CI $1 \cdot 46,3 \cdot 67$, respectively) in the fully adjusted models. Moreover, fair/poor self-rated oral health and having at least three oral health problems were associated with top quartile of percentage of energy content from saturated fat, and low intake of fruits and vegetables. Having $\geq 3$ oral health problems was associated with increased consumption of processed meat (OR 2.16, $95 \%$ CI 1.22, 3.18) after adjustment for confounders. This association did not remain after adjusting for energy intake. Furthermore, fair/poor self-rated oral health was associated with the bottom quartile of vitamin $\mathrm{C}$ in the fully adjusted model (OR 1.38, 95\% CI 1.04, 1.84) (see online Supplementary Appendix A, Fig. A1). Finally, having $\geq 3$ oral health problems was associated with the bottom quartile of $\alpha$-tocopherol in the fully adjusted models (see online
Supplementary Appendix A, Fig. A1). We did not observe other associations between oral health markers and vitamins and minerals.

Associations of markers of poor oral health with dietary intake in the HABC Study can be found in Table 4 and online Supplementary Appendix C, Fig. C1. Associations for oral health markers with processed meat are presented in online Supplementary Appendix B, Fig. B1.

Objective oral health markers. Periodontal disease (pocket depth) was associated with the top quartile of energy intake (OR $1.75,95 \%$ CI $1.29,2.37$ ) in the fully adjusted models (Table 4). Periodontal disease (loss of attachment) was the only oral health marker associated with the top quartile of percentage of energy content from saturated fat after adjustment (Table 4), whereas complete and partial tooth loss were associated with the top quartile of energy content from trans-fat (see online Supplementary Appendix C, Fig. C1). Moreover, complete tooth loss ( $0 v . \geq 21$ teeth) was associated with low intake of fruits and vegetables in the fully adjusted model (OR $1.55,95 \%$ CI 1.03 , 2.34) (Table 4). No significant associations were reported between poor oral health and low protein intake (see online Supplementary Appendix C, Fig. C1). Additionally, periodontal disease (pocket depth) was associated with increased intake of processed meat after adjustment for age, sex, race, education, smoking, alcohol, history of CVD and diabetes, and BMI. After adjusting further for energy intake, this association did not remain significant (see online Supplementary Appendix B, Fig. B1). We did not observe other associations between oral health markers and vitamins and minerals.

Subjective oral health markers. Having $\geq 3$ oral health problems was associated with the top quartile of energy intake (OR 1.49 , 95\% CI 1.04, 2.15) in the fully adjusted model. For micronutrients, only having $\geq 3$ oral health problems was associated with the bottom quartile of vitamin D intake (OR 1.77, $95 \%$ CI $1 \cdot 21,2 \cdot 58$, fully adjusted) (see online Supplementary Appendix A, Fig. A1). We did not observe other associations between oral health markers and vitamins and minerals.

Change in Elderly Dietary Index score and prevalence of oral health problems (10-year follow-up). The associations for change in EDI score over a 10-year follow-up (age 60-79 to 71-92 years), with poor oral health at 71-92 years, are presented in Table 5. In the age-adjusted model, persistent low EDI score (low score at both time points) was associated with partial tooth loss ( $<21$ teeth $v$. $\geq 21$ ), periodontal disease, fair/poor self-rated oral health and accumulation of oral health problems. After adjusting for confounders, associations for persistent low EDI score with tooth loss and having two oral health problems remained significant (OR 1.66, 95\% CI 1.09, 2.52; OR 1.96, $95 \%$ CI $1 \cdot 07,3 \cdot 56$, respectively).

\section{Missing data}

In the BRHS, those with missing data were slightly older (1 year), were more likely to be in manual social class, consumed less alcohol, were less physically active and were more likely to 
Table 3. Association of oral health markers with bottom quartile of energy intake, top quartile of percentage of energy from saturated fat and low intake of fruits and vegetables in older British men aged 71-92 years in the British Regional Heart Study (Odds ratios and $95 \%$ confidence intervals)

\begin{tabular}{|c|c|c|c|c|c|c|c|c|c|c|c|c|}
\hline & \multicolumn{4}{|c|}{$\begin{array}{l}\text { Top quartile of energy intake } \\
(2274-4965 \mathrm{kcal} / \mathrm{d}(9514-20774 \mathrm{~kJ} / \mathrm{d}))(\text { ( } 490 \text {; } \\
25 \%)\end{array}$} & \multicolumn{4}{|c|}{$\begin{array}{l}\text { Top quartile of \% of energy content from } \\
\text { saturated fat }(n 446 ; 25 \%) \\
(14.1-32.5 \%)\end{array}$} & \multicolumn{4}{|c|}{$\begin{array}{l}\text { Mean fruit and vegetable intake } \\
(<5 \text { portions } / \text { d) }(n 231 ; 11 \%)\end{array}$} \\
\hline & $\begin{array}{l}\text { Age- } \\
\text { adjusted } \\
\text { OR }\end{array}$ & $95 \% \mathrm{Cl}$ & $\begin{array}{l}\text { Fully } \\
\text { adjusted } \\
\text { OR }^{*}\end{array}$ & $95 \% \mathrm{Cl}$ & $\begin{array}{l}\text { Age- } \\
\text { adjusted } \\
\text { OR }\end{array}$ & $95 \% \mathrm{Cl}$ & $\begin{array}{l}\text { Fully } \\
\text { adjusted } \\
\text { OR }^{*}\end{array}$ & $95 \% \mathrm{Cl}$ & $\begin{array}{l}\text { Age- } \\
\text { adjusted } \\
\text { OR }\end{array}$ & $95 \% \mathrm{Cl}$ & $\begin{array}{l}\text { Fully } \\
\text { adjusted } \\
\text { OR }^{*}\end{array}$ & $95 \% \mathrm{Cl}$ \\
\hline \multicolumn{13}{|l|}{ Tooth loss } \\
\hline$\geq 21$ teeth & 1.00 & & 1.00 & & 1.00 & & 1.00 & & 1.00 & & 1.00 & \\
\hline $15-20$ teeth & 1.41 & $0.99,2.02$ & 1.54 & $1 \cdot 11,2 \cdot 16$ & 1.03 & $0.72,1.46$ & 0.95 & $0.65,1.37$ & 1.62 & $1.04,2.54$ & 1.70 & $1.04,2.78$ \\
\hline $8-14$ teeth & 1.49 & $1 \cdot 01,2 \cdot 19$ & 1.43 & $0.99,2.07$ & 1.37 & $0.95,1.98$ & 1.32 & $0.89,1.96$ & 1.55 & $0.95,2.53$ & 1.47 & $0.86,2.56$ \\
\hline $1-7$ teeth & 1.44 & $0.83,2.48$ & 1.26 & $0.75,2 \cdot 10$ & 1.62 & $1.00,2.64$ & 1.41 & $0.83,2.40$ & 1.19 & $0.59,2.38$ & 1.06 & $0.48,2.31$ \\
\hline 0 teeth & 1.31 & $0.89,1.92$ & 1.12 & $0.77,1.63$ & 0.89 & $0.62,1.29$ & 0.71 & $0.47,1.08$ & 2.01 & $1.29,3.11$ & 1.94 & $1.04,2.78$ \\
\hline \multicolumn{13}{|c|}{$\begin{array}{l}\text { Periodontal disease (\% of sites with loss of } \\
\text { attachment }>5.5 \mathrm{~mm} \text { ) }\end{array}$} \\
\hline$\leq 20 \%$ & 1.00 & & 1.00 & & 1.00 & & 1.00 & & 1.00 & & 1.00 & \\
\hline$>20 \%$ & 1.34 & $0.96,1.87$ & 1.19 & $0.86,1.63$ & 1.32 & $0.96,1.81$ & 1.27 & $0.90,1.79$ & 1.52 & $1 \cdot 00,2 \cdot 30$ & 1.52 & $0.96,2.40$ \\
\hline \multicolumn{13}{|l|}{ Self-rated oral health } \\
\hline Good/excellent & 1.00 & & 1.00 & & 1.00 & & 1.00 & & 1.00 & & 1.00 & \\
\hline Fair/poor & $1 \cdot 10$ & $0.83,1.44$ & $1 \cdot 10$ & $0.85,1.42$ & 1.38 & $1 \cdot 10,1 \cdot 74$ & 1.34 & $1.02,1.77$ & 1.55 & $1.16,2.06$ & 1.66 & $1 \cdot 16,2 \cdot 37$ \\
\hline \multicolumn{13}{|l|}{ Dry mouth symptoms } \\
\hline No dry mouth symptoms & 1.00 & & 1.00 & & 1.00 & & 1.00 & & 1.00 & & 1.00 & \\
\hline $1-2$ dry mouth symptom & 1.34 & $0.98,1.83$ & 1.27 & $0.95,1.70$ & 0.97 & $0.74,1.26$ & 0.95 & $0.69,1.31$ & 0.88 & $0.63,1.23$ & 0.82 & $0.54,1.24$ \\
\hline$\geq 3$ dry mouth symptoms & 1.49 & $1.08,2.06$ & 1.58 & $1.17,2 \cdot 13$ & 1.20 & $0.92,1.56$ & 1.29 & $0.93,1.78$ & 0.95 & $0.68,1.34$ & 1.05 & $0.69,1.60$ \\
\hline \multicolumn{13}{|c|}{ Cumulative oral health problems $\dagger$} \\
\hline 0 oral health problems & 1.00 & & 1.00 & & 1.00 & & 1.00 & & 1.00 & & 1.00 & \\
\hline 1 oral health problem & 1.49 & $1 \cdot 04,2 \cdot 14$ & 1.26 & $0.90,1.77$ & 1.32 & $0.94,1.83$ & $1 \cdot 18$ & $0.81,1.70$ & 1.32 & $0.87,2.02$ & 1.08 & $0.67,1.75$ \\
\hline 2 oral health problems & 1.33 & $0.88,2.01$ & 1.28 & $0.87,1.88$ & 1.50 & $1.05,2.15$ & 1.31 & $0.87,1.98$ & $1 \cdot 13$ & $0.70,1.81$ & 1.03 & $0.59,1.78$ \\
\hline$\geq 3$ oral health problems & $2 \cdot 15$ & $1.32,3.49$ & 2.32 & $1.46,3.67$ & 1.90 & $1.24,2.91$ & 1.68 & $1.01,2.78$ & 1.58 & $0.92,2.72$ & 1.60 & $0.84,3.07$ \\
\hline
\end{tabular}

*Age, social class, smoking, alcohol, history of CVD and diabetes, and BMl; for fruits and vegetables, energy intake was added in the model.

$\dagger<21$ remaining teeth, $\geq 3$ dry mouth symptoms, difficulty eating, sensitivity to hot/cold/sweets. 
Table 4. Association of oral health markers with bottom quartile of energy intake, top quartile of percentage of energy content from saturated fat and low intake of fruits and vegetables in older American men and women aged 71-80 years in the Health, Aging and Body Composition Study (Odds ratios and $95 \%$ confidence intervals)

\begin{tabular}{|c|c|c|c|c|c|c|c|c|c|c|c|c|}
\hline & \multicolumn{4}{|c|}{$\begin{array}{c}\text { Top quartile of energy intake } \\
(2270-8456 \mathrm{kcal} / \mathrm{d}(9498-35380 \mathrm{~kJ} / \mathrm{d})) \\
(n 678 ; 25 \%)\end{array}$} & \multicolumn{4}{|c|}{$\begin{array}{l}\text { Top quartile of \% of energy content from saturated fat } \\
\qquad(11-23 \%) \\
(n 678 ; 25 \%)\end{array}$} & \multicolumn{4}{|c|}{$\begin{array}{l}\text { Mean fruit and vegetable intake } \\
\qquad(<6 \text { portions/d) } \\
(\text { ( } 1789 ; 58 \%)\end{array}$} \\
\hline & $\begin{array}{l}\text { Age-adjusted } \\
\text { OR }\end{array}$ & $95 \% \mathrm{Cl}$ & $\begin{array}{l}\text { Fully adjusted } \\
\qquad \mathrm{OR}^{\star}\end{array}$ & $95 \% \mathrm{Cl}$ & $\begin{array}{l}\text { Age-adjusted } \\
\text { OR }\end{array}$ & $95 \% \mathrm{Cl}$ & $\begin{array}{l}\text { Fully adjusted } \\
\text { OR }^{\star}\end{array}$ & $95 \% \mathrm{Cl}$ & $\begin{array}{l}\text { Age-adjusted } \\
\text { OR }\end{array}$ & $95 \% \mathrm{Cl}$ & $\begin{array}{l}\text { Fully adjusted } \\
\qquad \mathrm{OR}^{\star}\end{array}$ & $95 \% \mathrm{Cl}$ \\
\hline \multicolumn{13}{|l|}{ Tooth loss } \\
\hline$\geq 21$ teeth & 1.00 & & 1.00 & & 1.00 & & 1.00 & & 1.00 & & 1.00 & \\
\hline $15-20$ teeth & 1.30 & $0.97,1.73$ & 1.14 & $0.84,1.54$ & 1.38 & $1.04,1.84$ & 1.26 & $0.93,1.70$ & 1.02 & $0.79,1.31$ & 0.94 & $0.71,1.24$ \\
\hline $8-14$ teeth & 1.42 & $1.05,1.93$ & 1.20 & $0.86,1.67$ & 1.32 & $0.96,1.81$ & $1 \cdot 18$ & $0.85,1.65$ & 1.31 & $0.99,1.74$ & 1.22 & $0.89,1.68$ \\
\hline $1-7$ teeth & 1.70 & $1.19,2.41$ & 1.34 & $0.92,1.97$ & 1.51 & $1 \cdot 05,2 \cdot 17$ & 1.32 & $0.90,1.94$ & 0.95 & $0.69,1.31$ & 0.87 & $0.59,1.27$ \\
\hline 0 teeth & 1.53 & $1.08,2 \cdot 16$ & 1.16 & $0.79,1 \cdot 70$ & 1.36 & $0.96,1.95$ & 1.08 & $0.73,1.60$ & 1.60 & $1 \cdot 15,2 \cdot 22$ & 1.56 & $1.03,2.34$ \\
\hline \multicolumn{13}{|c|}{ Periodontal disease } \\
\hline \multicolumn{13}{|c|}{$\begin{array}{l}\% \text { of sites with loss of attachment } \\
\geq 3 \mathrm{~mm}\end{array}$} \\
\hline$\leq 20 \%$ & 1.00 & & 1.00 & & 1.00 & & 1.00 & & 1.00 & & 1.00 & \\
\hline$>20 \%$ & $1 \cdot 20$ & $0.90,1.60$ & 1.00 & $0.74,1.36$ & 1.48 & $1.09,2.01$ & 1.48 & $1.09,2.01$ & 1.11 & $0.86,1.43$ & 0.94 & $0.70,1.25$ \\
\hline \multirow{2}{*}{\multicolumn{13}{|c|}{$\begin{array}{l}\% \text { of sites with pocket depth } \\
>3 \mathrm{~mm}\end{array}$}} \\
\hline $\begin{array}{l}\geq 3 \mathrm{~mm} \\
\leq 20 \%\end{array}$ & 1.00 & & & & & & & & & & & \\
\hline$>20 \%$ & 2.05 & $1.54,2.72$ & 1.75 & & 1.43 & & 1.00 & 00490 & 1.00 & م0 & 1.00 & 085110 \\
\hline \multicolumn{13}{|l|}{ Self-rated oral health } \\
\hline Good/excellent & 1.00 & & 1.00 & & 1.00 & & 1.00 & & 1.00 & & 1.00 & \\
\hline Fair/poor & $1 \cdot 22$ & $1.01,1.46$ & 1.00 & $0.81,1 \cdot 22$ & 0.82 & $0.67,1.01$ & 0.82 & $0.67,1.01$ & $1 \cdot 19$ & $1.00,1.42$ & 1.14 & $0.94,1.39$ \\
\hline \multicolumn{13}{|l|}{ Dry mouth } \\
\hline No & 1.00 & & 1.00 & & 1.00 & & 1.00 & & 1.00 & & 1.00 & \\
\hline Yes & $1 \cdot 13$ & $0.73,1.75$ & 1.15 & $0.73,1.82$ & 1.05 & $0.67,1.66$ & 1.05 & $0.67,1.66$ & 0.95 & $0.64,1.42$ & 1.06 & $0.68,1.67$ \\
\hline \multicolumn{13}{|c|}{ Cumulative oral health problems $\dagger$} \\
\hline 0 oral health problems & 1.00 & & 1.00 & & 1.00 & & 1.00 & & 1.00 & & 1.00 & \\
\hline 1 oral health problem & 1.51 & $1.22,1.88$ & 1.33 & $1.06,1.67$ & 1.20 & $0.96,1.50$ & $1 \cdot 20$ & $0.96,1.50$ & 1.09 & $0.91,1.31$ & 1.02 & $0.83,1.25$ \\
\hline 2 oral health problems & 1.48 & $1.11,1.97$ & 1.24 & $0.92,1.69$ & 0.94 & $0.69,1.28$ & 0.94 & $0.69,1.28$ & 1.31 & $1.01,1 \cdot 70$ & 1.22 & $0.91,1.62$ \\
\hline$\geq 3$ oral health problems & 1.83 & $1.30,2.56$ & 1.49 & $1 \cdot 04,2 \cdot 15$ & 1.06 & $0.73,1.52$ & 1.06 & $0.73,1.52$ & 1.28 & $0.93,1.76$ & 1.11 & $0.77,1.60$ \\
\hline
\end{tabular}

*Adjusted for age, sex, race, education, smoking, alcohol, history of CVD and diabetes, BMI; for fruits and vegetables, energy intake was added to the model.

$\dagger<21$ remaining teeth dry mouth when eating, any difficulty eating or chewing, limit of food due to gum problems. 
Table 5. Change in dietary quality (Elderly Dietary Index (EDI) scores) over 10 years (age 60-79 to 71-92 years) and the association with having oral health problems at 71-92 years in the British Regional Heart Study

(Odds ratios and $95 \%$ confidence intervals)

\begin{tabular}{|c|c|c|c|c|c|c|c|c|c|c|c|c|c|c|}
\hline \multirow[b]{2}{*}{$\begin{array}{l}\text { EDI change over } 10 \text { years } \\
\text { (60-79 years to } \\
71-92 \text { years) }\end{array}$} & \multicolumn{5}{|c|}{$\begin{array}{l}\text { Tooth loss }(<21 \text { teeth }) \\
\quad(n 933 ; 64 \%)\end{array}$} & \multicolumn{5}{|c|}{$\begin{array}{c}\text { Loss of attachment }(>20 \% \text { sites affected) } \\
(n 265 ; 24 \%)\end{array}$} & \multicolumn{4}{|c|}{$\begin{array}{l}\text { Self-rated oral health (fair/poor) } \\
\qquad(\text { 609; } n 34 \%)\end{array}$} \\
\hline & \multicolumn{2}{|c|}{$\begin{array}{l}\text { Age-adjusted } \\
\text { OR }\end{array}$} & $95 \% \mathrm{Cl}$ & $\begin{array}{l}\text { Eully adjusted } \\
\mathrm{OR}^{\star}\end{array}$ & $95 \% \mathrm{Cl}$ & $\begin{array}{l}\text { Age-adjusted } \\
\text { OR }\end{array}$ & $95 \% \mathrm{Cl}$ & \multicolumn{2}{|c|}{$\begin{array}{l}\text { Fully adjusted } \\
\mathrm{OR}^{\star}\end{array}$} & $95 \% \mathrm{Cl}$ & $\begin{array}{l}\text { Age-adjusted } \\
\text { OR }\end{array}$ & \multicolumn{2}{|r|}{$\begin{array}{l}\text { Fully adjusted } \\
\mathrm{OR}^{\star}\end{array}$} & $95 \% \mathrm{Cl}$ \\
\hline $\begin{array}{l}\text { Good score at both time } \\
\text { points }\end{array}$ & & 1.00 & & 1.00 & & 1.00 & & & 1.00 & & 1.00 & & 1.00 & \\
\hline $\begin{array}{l}\text { Score improved over } \\
10 \text { years }\end{array}$ & & $1 \cdot 70$ & $\cdot 20,2 \cdot 40$ & 1.41 & $0.97,2.06$ & 1.69 & $1.06,2.69$ & & 1.46 & $0.90,2.37$ & $1 \cdot 16$ & $0.83,1.63$ & $1 \cdot 17$ & $0.82,1.66$ \\
\hline $\begin{array}{l}\text { Score decreased over } \\
10 \text { years }\end{array}$ & & 1.91 & $32,2 \cdot 75$ & 1.61 & $1 \cdot 08,2 \cdot 38$ & 1.60 & $0.98,2.62$ & & 1.33 & $0 \cdot 80,2 \cdot 21$ & $1 \cdot 17$ & $0.84,1.64$ & 1.08 & $0.76,1.54$ \\
\hline \multirow[t]{3}{*}{$\begin{array}{l}\text { Low score at both time } \\
\text { points }\end{array}$} & & $2 \cdot 35$ & $.61,3.42$ & 1.66 & $1.09,2.52$ & 1.77 & $1 \cdot 08,2 \cdot 88$ & & 1.34 & $0 \cdot 78,2 \cdot 29$ & 1.44 & $1.03,2.01$ & $1 \cdot 31$ & $0.91,1.88$ \\
\hline & \multicolumn{14}{|c|}{ Cumulative oral health problems $\dagger$} \\
\hline & \multicolumn{3}{|c|}{$\begin{array}{c}1 \\
n 883 ; 46 \%\end{array}$} & \multicolumn{2}{|c|}{$\begin{array}{c}2 \\
n 471 ; 25 \%\end{array}$} & \multicolumn{2}{|c|}{$\begin{array}{c}\geq 3 \\
n 188 ; 10 \%\end{array}$} & \multicolumn{3}{|r|}{1} & \multicolumn{2}{|c|}{2} & \multicolumn{2}{|c|}{$\geq 3$} \\
\hline $\begin{array}{l}\text { EDI change over } 10 \text { years } \\
\text { (60-79 years to } 71-92 \text { years) }\end{array}$ & 0 & $\begin{array}{c}\text { Age- } \\
\text { adjusted OR }\end{array}$ & $95 \% \mathrm{Cl}$ & $\begin{array}{l}\text { Age- } \\
\text { adjusted OR }\end{array}$ & $95 \% \mathrm{Cl}$ & $\begin{array}{l}\text { Age- } \\
\text { adjusted OR }\end{array}$ & $95 \% \mathrm{Cl}$ & 0 & $\begin{array}{c}\text { Age- } \\
\text { adjusted OF }\end{array}$ & $95 \% \mathrm{Cl}$ & $\begin{array}{c}\text { Age- } \\
\text { adjusted OR }\end{array}$ & $95 \% \mathrm{Cl}$ & $\begin{array}{c}\text { Age- } \\
\text { adjusted OR }\end{array}$ & $95 \% \mathrm{Cl}$ \\
\hline $\begin{array}{l}\text { Good score at both time } \\
\text { points }\end{array}$ & 1.00 & 1.00 & & 1.00 & & 1.00 & & 1.00 & 1.00 & & 1.00 & & 1.00 & \\
\hline $\begin{array}{l}\text { Score improved over } \\
10 \text { years }\end{array}$ & 1.00 & 1.35 & $0.89,2.03$ & 1.51 & $0.96,2.39$ & 1.79 & $0.97,3.32$ & 1.00 & $1 \cdot 13$ & $0.73,1.76$ & 1.22 & $0.74,2.01$ & 1.35 & $0.70,2 \cdot 61$ \\
\hline $\begin{array}{l}\text { Score decreased over } \\
10 \text { years }\end{array}$ & 1.00 & 1.94 & $1.25,3.02$ & $2 \cdot 24$ & $1 \cdot 38,3.63$ & 2.50 & $1.33,4.69$ & 1.00 & 1.66 & $1.04,2.63$ & 1.81 & $1.08,3.03$ & 31.82 & $0.93,3.56$ \\
\hline $\begin{array}{l}\text { Low score at both time } \\
\text { points }\end{array}$ & 1.00 & 3.62 & $2 \cdot 21,5 \cdot 94$ & 2.95 & $1 \cdot 71,5 \cdot 09$ & $3 \cdot 17$ & $1 \cdot 59,6 \cdot 34$ & 1.00 & $2 \cdot 60$ & $1.52,4.45$ & 1.96 & $1.07,3.56$ & 2.04 & $0.96,4.33$ \\
\hline
\end{tabular}

*Age, social class, smoking, alcohol, history of CVD and diabetes, BMI, energy intake.

$\dagger<21$ remaining teeth, $\geq 3$ dry mouth symptoms, difficulty eating, sensitivity to hot/cold/sweets. 
report fair/poor general health. In the HABC Study, participants with missing data were more likely to be African American, current and former smokers, spent fewer years in school, consumed less alcohol and were more likely to report poor general health.

\section{Discussion}

In the present study, oral health problems in older age were associated with poor diet quality, higher intake of total energy, percentage of energy content from saturated and trans-fat, low intake of fruits and vegetables, and high intake of processed meat. Additionally, in the BRHS, persistent low diet quality in older ages over a 10-year follow-up was associated with having oral health problems later in life.

In the BRHS, tooth loss, fair/poor self-rated oral health and $\geq 3$ oral health problems were associated with poor diet quality (lowest EDI scores). Similar associations for tooth loss have been supported by previous studies ${ }^{(7,14)}$. Individuals experiencing tooth loss were more likely to reduce consumption of specific vegetables (such as apples, carrots) as well as foods high in fibre, which influence diet quality ${ }^{(10,50,51)}$. To our knowledge, this is one of the first studies to report an association between fair/poor self-rated oral health and diet quality. This highlights the importance of the individual's perception of the oral health status and that it is possible that older people with fair/poor self-rated oral health have unhealthier diets. Our results also indicate that a greater burden of oral health problems (an accumulation of oral health problems) is associated with poorer diet quality. No independent significant associations for oral health markers with diet quality were reported in the HABC Study. However, the small number of individuals in the low HEI score group could have influenced the significance of the results observed.

In the BRHS, dry mouth was associated with increased energy intake. Additionally, fair/poor self-rated oral health was associated with high intake of percentage of energy content from saturated fat and low intake of fruits and vegetables. These findings again indicate that self-reported measures of oral health could be indicators of a compromised diet. In the HABC Study, periodontal disease was associated with top quartiles of both total energy intake and percentage of energy content from saturated fat, in accordance with some previous studies $^{(52,53)}$. One study reported that increased intake of saturated fat was associated with progression of periodontal disease in older people ${ }^{(24)}$. Furthermore, tooth loss was associated with low intake of fruits and vegetables and top quartiles of percentage of energy content from trans-fat and energy content from sweets and soda. Additionally, in both studies, poor oral health was associated with high intake of processed meat. The associations for low intake of fruits and vegetables are in accordance with previous studies ${ }^{(7,8)}$. In both our study populations, overall, we observed an increased consumption of meat and fish, cakes/cookies/desserts as well as high intake of liquid and solid fats. Additionally, mean intakes of percentage of energy from saturated and trans-fat were above the current recommendations ${ }^{(47)}$. However, associations for poor oral health with processed meat did not remain significant after adjusting for energy intake, suggesting that older people with oral health problems may follow diets high in energy content and therefore are more likely to consume more processed meat too. We observed no associations between oral health markers and protein intake, which may be the result of overall levels of protein intake in both populations being within the recommended values ${ }^{(47)}$.

Persistent poor diet quality over 10 years of follow-up in the BRHS was associated with partial tooth loss and accumulation of oral health problems, an association that was independent of confounders. These findings point to a potential bidirectional relationship between poor oral health and diet in older age. A previous study reported that following a diet rich in antioxidants and vitamins and low in saturated and trans-fatty acids is linked to fewer teeth being lost ${ }^{(54)}$. The presence of oral health problems may lead to a compromised diet and poor diet quality due to food avoidance and change of dietary habits, whereas an unhealthy diet may also contribute to the deterioration of oral health in older people ${ }^{(55)}$.

A strength of our study is that we examined a wide range of macro- and micronutrients in two comparable studies of community-dwelling older people in two Western populations and were able to investigate bidirectional associations between poor oral health and diet quality in the BRHS. Moreover, this is one of the few studies examining the role of subjective oral health measures, such as dry mouth and self-rated oral health.

Our study has also limitations. Measurement of some oral health measures (i.e. periodontal disease, dry mouth) was different in the two studies, and some dietary intake variables (i.e. energy content from trans-fat, micronutrients) were not available in both studies. Furthermore, different measures assessed diet quality in the two studies (EDI in BRHS; HEI in HABC Study), and therefore this may account for differences in the diet quality results between the two studies. It is also possible that our findings may not be representative of the general populations of the UK and USA because the BRHS consisted of White males, whereas the HABC Study comprised a subpopulation of older people in the USA (White and African American males and females from Pittsburgh and Memphis). The majority of our findings were cross-sectional, and therefore cannot establish causal relationships. When dietary intake is assessed by self-reported measures, including the FFQ method, it can lead to misreporting of intakes and this can introduce bias in the form of measurement error $^{(56,57)}$. This could influence the estimation of energy and micronutrient intakes ${ }^{(56,57)}$. Nevertheless, the FFQ used in the present study have been validated in the British and US populations ${ }^{(31,36,58)}$. We did not exclude participants with unintentional weight loss or extreme energy intake. However, in both studies, very small number of participants reported unintentional weight loss due to cancer or heart failure (BRHS $n 59,2 \cdot 7 \%$; HABC Study $n 13,0.4 \%$, for cancer) or excessive energy intake (BRHS $n 2$, $0 \cdot 1 \%$; HABC Study $n 77,2.6 \%$ ). Therefore, the results are unlikely to be biased due to unintentional weight loss or extreme energy intake. Furthermore, the presence of survivor bias is possible, since healthier participants are more likely to have attended the examinations. We also adjusted for a range of confounders, but residual confounding may be present, resulting in overestimation of the observed associations. In both studies, multiple comparisons were performed, therefore increasing the risk of false-positive results. As the number of hypothesis 
testing increases, so does the risk of observing false-positive results ${ }^{(59)}$.

In conclusion, we observed that oral health problems were associated with poor diet quality and intake of micro- and macronutrients in two studies of community-dwelling older people in the UK and USA. Also, persistent poor diet quality was found to be associated with poor oral health later in life in the BRHS. These findings support a bidirectional association between poor oral health and diet. Future studies should further investigate the association between changes in diet and changes in oral health in older people. Additionally, future research should also focus on older people living in care homes to provide more evidence on how oral health influences diet and food choices. Further evidence can help design effective dietary programmes tailored to the oral health of older people, which could reduce the burden of poor oral health and its consequences in older people.

\section{Acknowledgements}

This research was supported by the British Heart Foundation Programme grant (RG/08/013/25942), The Dunhill Medical Trust (grant no. R396/1114 and R592/0717) and the National Institute on Aging (contracts N01-AG-6-2101; N01-AG-6-2103; N01-AG-6-2106; NIA grant R01-AG028050; NINR grant R01NR012459; NIH/NIDCR grant R03 DE028505-02). The British Heart Foundation, Dunhill Medical Trust and National Institute on Aging had no role in the design, analysis or writing of this article.

Study concept and design: E. K., S. E. R., S. G. W., A. O. P. and P. H. W. Acquisition of data: S. E. R., S. G. W., A. O. P., P. H. W., L. T. L. and R. J. W. Analysis and interpretation of data: all authors. Drafting of the manuscript: all authors. Critical revision of the manuscript for important intellectual content: all authors.

The authors declare that there are no conflicts of interest.

\section{Supplementary material}

For supplementary materials referred to in this article, please visit https://doi.org/10.1017/S0007114521000180

\section{References}

1. Ramsay SE, Whincup PH \& Watt RG (2015) Burden of poor oral health in older age: findings from a population-based study of older British men. BMJ Open 5, e009476.

2. Kotronia E, Wannamethee SG, Papacosta AO, et al. (2019) Oral health, disability and physical function: results from studies of older people in the United Kingdom and United States of America. J Am Med Dir Assoc 20, 1654.e1651-1654.e1659.

3. Cullinan MP \& Seymour GJ (2013) Periodontal disease and systemic illness: will the evidence ever be enough? Periodontology 62, 271-286.

4. Joshy G, Arora M \& Korda RJ (2016) Is poor oral health a risk marker for incident cardiovascular disease hospitalisation and all-cause mortality? Findings from 172630 participants from the prospective 45 and Up Study. BMJ Open 6, e012386.

5. Moynihan PJ (2007) The relationship between nutrition and systemic and oral well-being in older people. J Am Dent Assoc 138, 493-497.
6. Hung H-C, Colditz G \& Joshipura KJ (2005) The association between tooth loss and the self-reported intake of selected CVD-related nutrients and foods among US women. Community Dent Oral Epidemiol 33, 167-173.

7. Ritchie CS, Joshipura K, Hung H-C, et al. (2002) Nutrition as a mediator in the relation between oral and systemic disease: associations between specific measures of adult oral health and nutrition outcomes. Crit Rev Oral Biol Med 13, 291-300.

8. Tsakos G, Herrick K, Sheiham A, et al. (2010) Edentulism and fruit and vegetable intake in low-income adults. J Dent Res $\mathbf{8 9}$, 462-467.

9. Yoshida M, Kikutani T, Yoshikawa M, et al. (2011) Correlation between dental and nutritional status in community-dwelling elderly Japanese. Geriatrics Gerontol Int 11, 315-319.

10. Watson S, McGowan L, McCrum L-A, et al. (2019) The impact of dental status on perceived ability to eat certain foods and nutrient intakes in older adults: cross-sectional analysis of the UK National Diet and Nutrition Survey 2008-2014. Int J Behav Nutr Phys Activity 16, 43.

11. Savoca MR, Arcury TA Leng X, et al. (2010) Association between dietary quality of rural older adults and self-reported food avoidance and food modification due to oral health problems. J Am Geriatrics Soc 58, 1225-1232.

12. Savoca MR, Arcury TA, Leng X, et al. (2009) Severe tooth loss in older adults as a key indicator of compromised dietary quality. Public Health Nutr 13, 466-474.

13. Rohrmann $S \&$ Linseisen J (2016) Processed meat: the real villain? Proc Nutr Soc 75, 233-241.

14. Zhu Y \& Hollis JH (2014) Tooth loss and its association with dietary intake and diet quality in American adults. J Dent $\mathbf{4 2}$, 1428-1435.

15. Bomfim RA, de Souza LB \& Corrente JE (2018) Tooth loss and its relationship with protein intake by elderly Brazilians: a structural equation modelling approach. Gerodontology 35, 51-58.

16. Gaewkhiew P, Sabbah W \& Bernabé E (2017) Does tooth loss affect dietary intake and nutritional status? A systematic review of longitudinal studies. J Dent 67, 1-8.

17. Ervin RB \& Dye BA (2009) The effect of functional dentition on healthy eating index scores and nutrient intakes in a nationally representative sample of older adults. J Public Health Dent 69 , $207-216$.

18. Iwasaki M, Yoshihara A, Ogawa H, et al. (2016) Longitudinal association of dentition status with dietary intake in Japanese adults aged 75 to 80 years. J Oral Rehabilitation 43, 737-744.

19. Sheiham A, Steele JG, Marcenes W, et al. (2001) The relationship among dental status, nutrient intake, and nutritional status in older people. J Dent Res 80, 408-413.

20. Iwasaki M, Kimura Y, Yoshihara A, et al. (2015) Association between dental status and food diversity among older Japanese. Community Dent Health 32, 104-110.

21. Hamasaki T, Kitamura M, Kawashita Y, et al. (2017) Periodontal disease and percentage of calories from fat using national data. J Periodontal Res 52, 114-121.

22. Iwasaki M, Yoshihara A, Ito K, et al. (2016) Hyposalivation and dietary intake. Geriatrics Gerontology Int 16, 500-507.

23. Iwasaki M, Borgnakke WS, Ogawa $\mathrm{H}$, et al. (2018) Effect of lifestyle on 6-year periodontitis incidence or progression and tooth loss in older adults. J Clin Periodontol 45, 896-908.

24. Iwasaki M, Manz MC, Moynihan P, et al. (2011) Relationship between saturated fatty acids and periodontal disease. J Dent Res 90, 861-867.

25. Woelber JP, Bremer K, Vach K, et al. (2016) An oral health optimized diet can reduce gingival and periodontal inflammation in humans - a randomized controlled pilot study. BMC Oral Health 17, 28. 
26. Lennon LT, Ramsay SE, Papacosta O, et al. (2015) Cohort profile update: the British Regional Heart Study 1978-2014: 35 years follow-up of cardiovascular disease and ageing. Int $J$ Epidemiol 44, 826-826g.

27. Association WM (2013) World Medical Association Declaration of Helsinki: ethical Principles for Medical Research Involving Human Subjects. JAMA 310, 2191-2194.

28. Stewart R, Weyant RJ, Garcia ME, et al. (2013) Adverse oral health and cognitive decline: the health, aging and body composition study. J Am Geriatrics Soc 61, 177-184.

29. Weyant RJ, Newman AB, Kritchevsky SB, et al. (2004) Periodontal disease and weight loss in older adults. $J \mathrm{Am}$ Geriatrics Soc 52, 547-553.

30. Thomson WM, Chalmers JM, Spencer AJ, et al. (1999) The Xerostomia Inventory: a multi-item approach to measuring dry mouth. Community Dent Health 16, 12-17.

31. Yarnell JW, Fehily AM, Milbank JE, et al. (1983) A short dietary questionnaire for use in an epidemiological survey: comparison with weighed dietary records. Hum Nutr Appl Nutr 37, 103-112.

32. Parsons TJ, Papachristou E, Atkins JL, et al. (2019) Healthier diet quality and dietary patterns are associated with lower risk of mobility limitation in older men. Eur J Nutr $\mathbf{5 8}$ $2335-2343$.

33. Atkins JL, Whincup PH, Morris RW, et al. (2014) High diet quality is associated with a lower risk of cardiovascular disease and all-cause mortality in older men. J Nutr 144, 673-680.

34. Holland B, Welch A, Unwin I, et al. (1991) McCance and Widdowson's the Composition of Foods. Cambridge: Royal Society of Chemistry.

35. Block G, Hartman AM, Dresser CM, et al. (1986) A data-based approach to diet questionnaire design and testing. Am J Epidemiol 124, 453-469.

36. Hengeveld LM, Wijnhoven HAH, Olthof MR, et al. (2018) Prospective associations of poor diet quality with long-term incidence of protein-energy malnutrition in communitydwelling older adults: the Health, Aging, and Body Composition (Health ABC) Study. Am J Clin Nutr 107, 155-164.

37. Bowman SA, Lino M, Gerrior SA, et al. (1998) The Healthy Eating Index, 1994-96. Fam Econ Nutr Rev 11, 2.

38. Ramsay SE, Whincup PH, Watt RG, et al. (2015) Burden of poor oral health in older age: findings from a population-based study of older British men. BMJ Open 5, e009476.

39. Ruhl CE, Harris TB, Ding J, et al. (2007) Body mass index and serum leptin concentration independently estimate percentage body fat in older adults. Am J Clin Nutr 85, 1121-1126.

40. Parsons TJ, Sartini C, Welsh P, et al. (2017) Physical activity, sedentary behavior, and inflammatory and hemostatic markers in men. Med Sci Sports Exerc 49, 459-465.

41. Joint Formulary Committee; Royal Pharmaceutical Society of Great Britain (2012) British National Formulary. London: Pharmaceutical Press.

42. Hobdell M, Petersen PE, Clarkson J, et al. (2003) Global goals for oral health 2020. Int Dent J 53, 285-288.

43. Bretz WA, Weyant RJ, Corby PM, et al. (2005) Systemic inflammatory markers, periodontal diseases, and periodontal infections in an elderly population. I Am Geriatric Soc $\mathbf{5 3}$ $1532-1537$.
44. Ramsay SE, Papachristou E, Watt RG, et al. (2018) Influence of poor oral health on physical frailty: a population-based cohort study of older British men. J Am Geriatrics Soc 66, 473-479.

45. Thompson FE \& Subar AF (2008) Dietary assessment methodology. In Nutrition in the Prevention and Treatment of Disease, pp. 5-48 [A Coulston and C Boushey, editors]. San Diego, CA: Academic Press.

46. Department of Health (1991) Dietary Reference Values for Food Energy and Nutrients for the United Kingdom. Report of the Panel on Dietary Reference Values of the Committee on Medical Aspects of Food Policy. Reports on Health and Social Subjects, vol. 41. London: TSO. https://assets.publishing. service.gov.uk/government/uploads/system/uploads/attachment_ data/file/743786/Dietary_Reference_Values_for_Food_Energy_ and_Nutrients_for_the_United_Kingdom_1991_.pdf (accessed February 2021).

47. Institute of Medicine, Food and Nutrition Board (2005) Dietary Reference Intakes: Energy, Carbohydrate, Fiber, Fat, Fatty Acids, Cholesterol, Protein, and Amino Acids. Washington, DC: The National Academies Press.

48. Food Standards Agency (2016) United Kingdom Eatwell Plate. https://www.food.gov.uk/business-guidance/the-eatwell-guideand-resources (accessed November 2020).

49. U.S. Department of Health and Human Services \& U.S. Department of Agriculture (2015) 2015-2020 Dietary Guidelines for Americans, 8th ed. https://health.gov/our-work/food-andnutrition/2015-2020-dietary-guidelines/ (accessed December 2015).

50. Sheiham A \& Steele J (2001) Does the condition of the mouth and teeth affect the ability to eat certain foods, nutrient and dietary intake and nutritional status amongst older people? Public Health Nutr 4, 797-803.

51. Moynihan PJ, Snow S, Jepson NJ, et al. (1994) Intake of non-starch polysaccharide (dietary fibre) in edentulous and dentate persons: an observational study. $\mathrm{Br}$ Dent $J$ 177, 243-247.

52. Najeeb S, Zafar MS, Khurshid Z, et al. (2016) The role of nutrition in periodontal health: an update. Nutrients $\mathbf{8}, 530$.

53. Jauhiainen L, Suominen AL, Kanerva N, et al. (2016) Periodontal pocketing and gingival bleeding in relation to Nordic diet - results from a population-based survey. J Clin Periodontol 43, 1013-1023.

54. Kotsakis GA, Chrepa V, Shivappa N, et al. (2018) Diet-borne systemic inflammation is associated with prevalent tooth loss. Clin Nutr 37, 1306-1312.

55. Moynihan $P$ (2005) The interrelationship between diet and oral health. Proc Nutr Soc 64, 571-580.

56. Poslusna K, Ruprich J, de Vries JHM, et al. (2009) Misreporting of energy and micronutrient intake estimated by food records and 24 hour recalls, control and adjustment methods in practice. Br J Nutr 101, S73-S85.

57. Livingstone MBE \& Black AE (2003) Markers of the validity of reported energy intake. J Nutr 133, 895S-920S.

58. Ahluwalia N, Dwyer J, Terry A, et al. (2016) Update on NHANES dietary data: focus on collection, release, analytical considerations, and uses to inform public policy. Adv Nutr 7, 121-134.

59. Lindquist MA \& Mejia A (2015) Zen and the art of multiple comparisons. Psychosom Med 77, 114-125. 